\title{
Design and Development of Integrated Electronic Sport (E-Sport) Event Management Platform
}

\author{
Randy Anthony, Timotius Eka Valentino, James Purnama, Maulahikmah Galinium \\ randy.anthony@sgu.ac.id, timotius.valentino@student.sgu.ac.id, james.purnama@sgu.ac.id, \\ maulahikmah.galinium@sgu.ac.id \\ Faculty of Engineering and Information Technology, Swiss German University, Tangerang, Indonesia
}

\begin{abstract}
E-sport or electronic sport is competitive video gaming. Current largest e-sport competition based on its prize pool is The International 2018 with $\$ 25,532,177$. In Indonesia, e-sport is supported by State Minister of Youth and Sports Affairs, Ministry of Communication and Informatics and Ministry of Industry. However, event organizers agree that current e-sport management platforms are limited to manage tournaments bracket and scheduling without capability to get event's location information, finding sponsors and inviting players and workers. Therefore, the purpose of this research is to create a website to handle them and also integrate it with a database that contains information of e-sport community members such as event organizers, workers, players, sponsors, and tournament location providers. After website development is done, the website is tested with usability testing in order to prove the hypothesis. After the testing is done to ten samples (four event organizers, four e-sport workers and four e- sport players). Event organizers consider this website still has missing features and the user interface and user experience are not good enough. On the other hand, e-sport players and workers consider this will help them if the website has launched.
\end{abstract}

Keywords: Electronic Sports, Event Management, Event Organizer

\section{Introduction}

E-sport (short for electronic sport) is competitive video gaming. Competitions can be held through multiple types of platforms such as: classic arcade, personal computer, mobile phone and so forth. In Indonesia, the largest competitions by its prize pool is the Indonesia Games Championship 2019 which its total prizes is three billion rupiah. [1]. In 2018, e- Sport officially became one of the sports of the Asian Games. There are two Indonesian medallists, Ridel Sumarandak, who got a gold medal from the Clash Royale game (card tower defense mobile game which developed and published by Supercell) and Hendry Handisurya, who got a silver model from the Hearthstone game (online card game that developed and published by Blizzard Entertainment) [2]. E-sport is also already supported by State Minister of Youth and Sports Affairs, Ministry of Communication and Informatics and Ministry of Industry. From education sector, currently there are two schools who have already made e-sport one of their subjects, PSKD 1 in Central Jakarta and Bina Bangsa in Malang [3]. By looking at the potential of the e-sport industry, it is hoped this research will contribute towards developing the e-sport industry in Indonesia. A website platform is proposed to manage electronic sport events and integrate it with a database that contains data of e-sport community members such as event organizers, workers, players, sponsors and tournament location information. 
Reference [4] developed a web application by using .NET framework, HTML and CSS as their front-end, C\# as business logic and Microsoft SQL Server as a connector between front-end and back-end. This application has the capability to do user registration and manage it, track tournament progress, adapt user's time zone in order to avoid tournament misscheduling and have a mechanism to log and handle disputes between match results. Also, a web application will be supported by a mobile application but its functionalities are limited to take pictures of match results and forward it to website, check the schedule for upcoming matches and tournaments and as a disputes logger. The role of the user in this application is divided into two: regular user and administrator. The regular user will have the capability to manage his profile, enter or quit leagues, make, enter or quit teams and tournaments, check the tournament leader board, upload match results and as a dispute logger if results have been uploaded. As administrator, it has the capability to create another administrator user, create tournaments in a league, schedule knockout tournaments, schedule round-robin tournament and resolve disputes. In the administrator role, it can be seen that there are two types of tournament, knockout tournament, in which teams compete against each other and only the winning team moves to the next round from each match and round-robin tournament which is a tournament in which each team plays once and the winner is calculated as the team that has won most matches.

\section{Method}

A. Business Analaysis and Design: Business analysis that is conducted for this method uses Smart Business Map (short for SBM) [5]. Smart Business Map is produced by doing analysis of following factors:

1. Problem to solve

2. Who has the problem?

3. How big is the market?

4. How to solve the problem?

5. Unique selling propositions

B. User Requirement Validation: After getting the overview of the market based on personal assumption and understand what probably their problems are. Author needs to validate if that assumption in order to get to know the real problems that they face and develop a system that is really needed and this part is conducted by distributing questionnaires and also doing surveys.

C. System Design: Based on user requirement validation data, Unified Modelling Language (UML) diagram will be created in order to represent the overview of the system and Entity Relational Diagram (ERD) will also be created to get the overview of database structure.

D. System Development :The platform is developed by using four main tools: Figma - a drag and drop design tool that is used to design user interface, Laravel - an open source web application framework, Jetbrains Webstorm - a web development integrated development environment (IDE) and MySQL - a relational database that is developed by Oracle.

$\boldsymbol{E}$. Usability Testing: A technique of testing that aims to measure of how easy is the system to be used by end users. The ease of the system will be tested using Likert scale which is a rating scale type that used to measure opinions/attitudes. 


\section{Result \& Discussions}

\section{A. Business Analysis and Design}

1. Problem to Solve: The problem that this platform tries to solve is decentralized esport event management. By decentralized, it means that they still do not have one specific media to handle promotion, search for e-sport workers (commentator, judges and others) and any others features e-sport event management may have.

2. Who has the problem?: The first problem comes from e-sport event organizers. The problem that they face, especially for the amateur, is they do not have a centralized platform that integrates one e-sport community member with others. For instance, an event organizer wants to invite e-Sport athletes to join their event. However, the media that they use is just their own social media and website and also to market their events in order to attract e-Sport enthusiast and athletes. The second problem comes from e-sport workers and enthusiasts, since they have no centralized e-sport event promotion. They only know about e-sport event from event organizer's social media and websites and this can be bothersome since e-sport workers and enthusiasts need to search for events by visiting social media and websites from one event organizer to another.

3. How Big is the Market?: Eventbrite and Maimilu is considered as a competitor of planned platform. Both are event management platform that can include promotion and ticketing. However, planned platform is focused on e-sport competition while the others are for general event.

4. How to Solve the Problem?: The first problem can be solved by gathering all e-sport community members in one platform. The purpose of this platform is to connect all of its components so they will have no difficulty to communicate with one another. The second problem can be solved by the first solution. Since all of e-sport components have been connected, it can be easier to promote the events and e-sport enthusiasts and workers can find and join tournaments easily.

5. Unique Selling Proposition: Compared to the existing platform that has the same field as this platform, there are several unique features that it offers to their users. First, this platform is integrated to a website that loads information of its users, such as event organizer, e-sport athletes and any other e-sport community members. With this integration, the user that wants to create an e-sport event can broadcast their event to those users. Second, with the platform, it will be managing the event such as streaming channel, news, sponsor, participant and worker. Those features are not available in the competitors.

\section{B. User Requirement Validation}

Total two interviews have been conducted and four questionnaires have been answered by e-sport event organizers. Interviews are done after interviewer presenting the idea and showing mock-up. While questionnaires are made in Google Forms and there is already explanation about features of the platform that will be developed inside it. These are the points summarized from their answers:

1. One of them is not using any kind of platform and the others are using tournament management platform which has feature to handle tournament bracket and record its results

2. Current platform does not have feature to manage event location and they need to negotiate and ask for availability to each location.

3. To invite and manage participant in e-sport event, they would like to have a platform 
which can be a dedicated e-sports social media which integrated to gaming platform and in term of event management, they would like to have feature to store participants history, automated message relay and schedule management.

4. To find sponsors for e-sport event, they would like to have a platform that is supported by game developers and publishers since this kind of support could result in sponsorship deals and also a feature to automate list of sponsors that want to support an event.

5. To attract viewers, they would like to have a platform with social media integration and a feature to notify viewers if the match has started so viewers can watch it on provided stream link.

6. To get e-sport workers (commentator, spectator, admin, etc.) for e-sport events, they would like to have a platform that can differentiate levels of e- sport workers (beginner or expert).

\section{System Design}

Event management that can be handled by this platform is to manage and broadcast job vacancy to related workers, broadcast event to all e-sport community members and also define sponsorship package for event and broadcast it to selected industry. The first process of this platform is started from event organizer by creating an event and after event organizer has created an event, event organizer can proceed to either open its job vacancy or publish the event or add sponsorship package. By opening job vacancy, event organizer let workers know about what the event needs and what is the criteria and if workers meet the criteria, they can register to the event and it will be reconfirmed by event organizer and after all of vacancy is filled, event organizer can close the vacancy. By publishing event, event organizer let e-sport enthusiast and player know about the event and its details such as: where it is, when it is, what games that is contested, registered players, winners, sponsors and its streaming channels. By adding sponsorship package, event organizer defines the agreements if companies want to sponsor their event and after that is define, event organizer can publish it either to all sponsors or only certain industry and after that sponsor can response if they are interested or not.

\section{System Development}

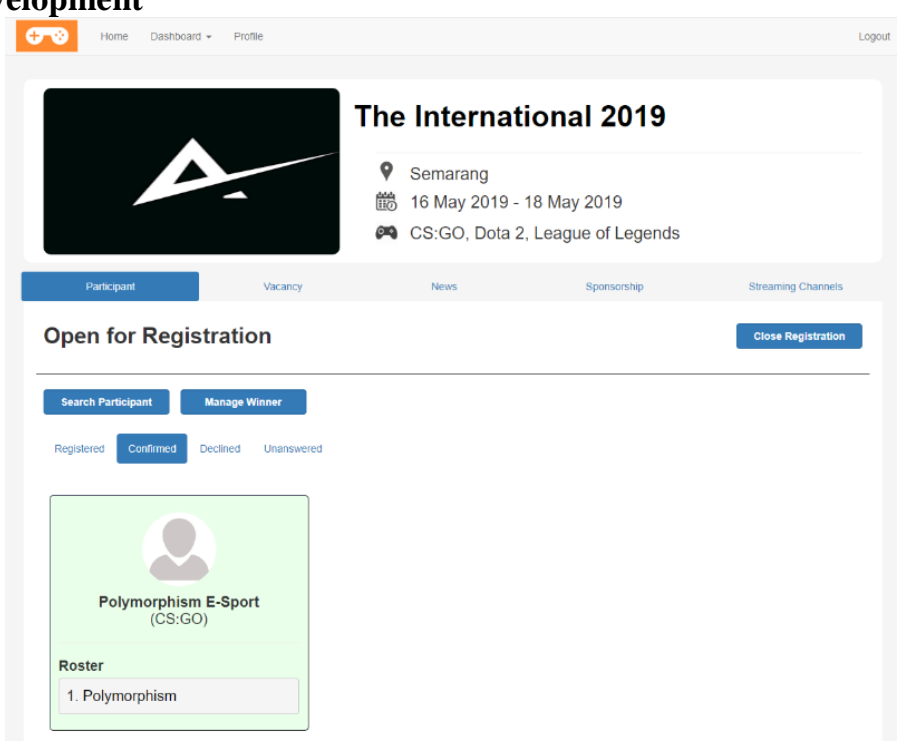

Figure 1. Participant Management Page 
Besides participant management as it is shown in Fig. 1, event vacancy, news, sponsorship and streaming channel can also be managed as those features also already designed in previous step. Fig. 2 shows list of members in e-sport community that can be invited to events. Since this platform handles participant, worker and sponsor management. This platform stores their data along with their details that they fill during registration. With this diversity of data, event organizers can filter and choose which ones to invite to their event. Another feature that this platform has is e-sport career track record which means every event participation is recorded as the example can be seen in Fig 3. Event organizer will have list of their managed events, e-sport worker and player will have list of their participation or achievement and sponsor will have list of their sponsored events and the track record can be seen by the entire e-sport community.

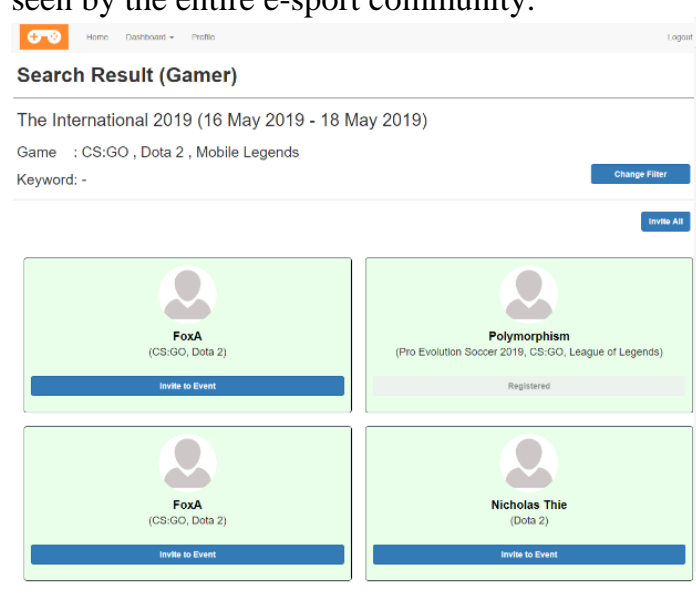

Figure 2. Participant Search Result

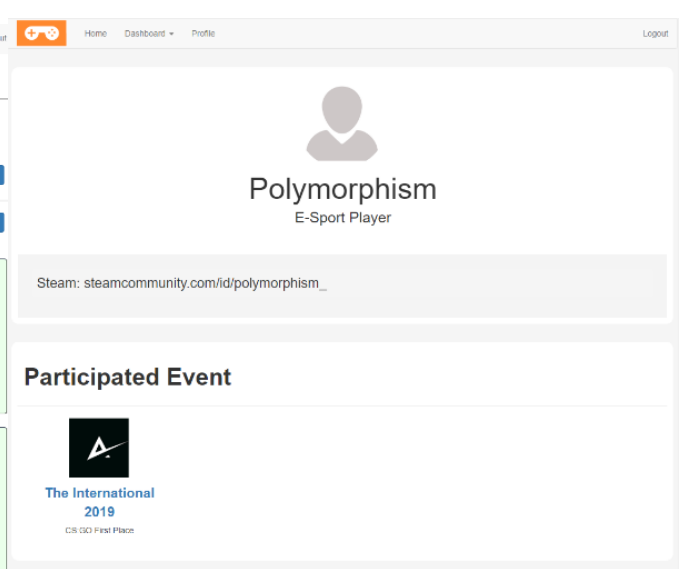

Figure 1. E-Sport Player Profile Page (with Achievement)

\section{E. Usability Testing}

Respondents for this platform were four e-sport event organizers (EO for short) as the result can be seen in Table I and Table II, four players as the result can be seen in Table III and Table IV and two workers as the result can be seen in Table V and Table VI. This testing was done by means of respondents using the specified features without instructions on how to use them and giving their opinion about the level of difficulty and also feedback on those features. Easiness level is measured using a scale from one to five, where one is the very difficult and five is the very easy.

Scale description: (1 - Very difficult until 5 - Very easy)

Table I. Feature Easiness Level (Event Organizer - EO)

\begin{tabular}{lccccc}
\hline Feature Name & EO\#1 & EO\#2 & EO\#3 & EO\#4 & Overall Score \\
\hline Find worker and invite them to work for predefined event & 4 & 3 & 3 & 5 & $15 / 20=75 \%$ \\
$\begin{array}{l}\text { Find player and invite them to be participant for } \\
\text { predefined event }\end{array}$ & 5 & 3 & 3 & 5 & $16 / 20=80 \%$ \\
Find sponsor and invite them to predefined event & 3 & 3 & 3 & 5 & $14 / 20=70 \%$ \\
\hline
\end{tabular}

Table II. Features Comments from E-Sport Event Organizer

\begin{tabular}{ll}
\hline Testing Case: Find worker and invite them to work for predefined event \\
\hline 1 & Include their experience \\
2 & User experience and interface and needs more details description
\end{tabular}


3 Addition feature such as optional message for briefing needs to be added. Also, details about their social media or their location is still not available yet.

4 No comment

Testing Case: Find player and invite them to be participant for predefined event

1 No comment

2 User experience and interface and needs more details description

3 List of players should be in the form of a list with sufficient detail, for profiles and social media can be made into animated hover. Also add filter options such as age and nationality. Just like recruiting worker, add optional message features to player briefings.

4 No comment

Testing Case: Find sponsor and invite them to predefined event

1 Include additional column to be filled by the sponsor themselves

2 User experience and interface and needs more details description

3 Upload proposal feature is still not available. Since generally, event organizers invite sponsors by sending proposal. Also, "local sponsors" optional filter should be added if event organizers only have non-international proposal.

4 No comment

Testing Case: General aspect of this website

1 In doubt for sponsorship feature since EO\#1 thinks it is a confidential information about an event. Also, this platform needs more memorable logo and better user interface.

2 More interesting user interface

3 From user interface side, it is still not intuitive. For instance, after logged in as event organizer, it should be redirected to dashboard unlike player/worker account. Also, to invite player/worker, EO cannot do it directly from dashboard but needs to go to certain event management page first.

4 Website design should be not too simple but also not too complicated.

Table III. Features Easiness Level (E-sport Player)

\begin{tabular}{|c|c|c|c|c|c|}
\hline \multirow[t]{2}{*}{ Feature Name } & \multicolumn{4}{|c|}{ Easiness Level } & \multirow{2}{*}{ Overall Score } \\
\hline & Player\#1 & Player\#2 & Player\#3 & Player\#4 & \\
\hline $\begin{array}{l}\text { Browse e-sport event that they consider } \\
\text { interesting }\end{array}$ & 4 & 5 & 5 & 5 & $19 / 20=95 \%$ \\
\hline Register to an event & 4 & 5 & 5 & 5 & $19 / 20=95 \%$ \\
\hline Check participant registration status & 4 & 5 & 5 & 5 & $19 / 20=95 \%$ \\
\hline
\end{tabular}

Table IV. Features Comments (E-sport Player)

\begin{tabular}{llll}
\hline \multicolumn{2}{l}{ Testing Case: Browse e-sport event that they consider interesting } & \multicolumn{2}{l}{ Testing Case: Register to an event } \\
\hline 1 & No comment & 1 & No comment \\
2 & No comment & 2 & No comment \\
3 & No comment & 3 & No comment \\
4 & No comment & 4 & No comment \\
\hline \multicolumn{2}{l}{ Testing Case: Check participant registration status } & \multicolumn{2}{l}{ Testing Case: General aspect of this website } \\
\hline 1 & No comment & 1 & No comment \\
2 & No comment & 2 & More interesting user interface \\
3 & No comment & 3 & No comment \\
4 & No comment & 4 & No comment \\
\hline
\end{tabular}

Table V. Features Easiness Level (E-sport Worker)

\begin{tabular}{lccc}
\hline Feature Name & \multicolumn{2}{c}{ Easiness Level } & \multicolumn{2}{c}{ Overall } & \\
& Worker\#1 & Worker\#2 & Score \\
\hline Browse e-sport event that they consider interesting & 5 & 5 & $10 / 10=100 \%$ \\
Register to an event & 5 & 5 & $10 / 10=100 \%$ \\
Check registration status as worker & 5 & 5 & $10 / 10=100 \%$ \\
\hline
\end{tabular}

Table VI. Features Comments (E-sport Worker)

Testing Case: Browse e-sport event that they consider interesting 


\begin{tabular}{ll}
\hline 1 & No comment \\
2 & More information such as prize pool, invited guest and contact person should be added to event details. \\
\hline \multicolumn{2}{c}{ Testing Case: Register to an event } \\
\hline 1 & No comment \\
2 & No comment \\
\hline \multicolumn{2}{c}{ Testing Case: Check registration status } \\
\hline 1 & No comment \\
2 & No comment \\
\hline \multicolumn{2}{l}{ Testing Case: General aspect of this website } \\
\hline 1 & Improve user interface and adds more initial categorization (e.g.: gender or age) \\
2 & No comment \\
\hline
\end{tabular}

\section{Conclusion}

An event management platform named Geeksports has been developed as a result of this research. This platform can manage events in a part of news, streaming channel, participant, worker and sponsor. Integration with e- sport community database has also been done and therefore e-sport event organizer, sponsor, worker, player and enthusiast can see one with another profile along with experience and achievement. The event organizer also can publish their event to e-sport community and invite them either as player, worker or sponsor to their event. In addition, from usability testing result, all players and workers think this platform is easy to use and they will use it if the website is already launched. However, some event organizers think that the system's user interface is not interesting and still have some missing features. Also, there are mixed responses regarding the sponsorship features, an alternative scheme might need to be developed to be able to provide better confidentiality for the event organizer's data. Also, testing should be done again to event organizer after platform has been improved based on feedback. Also, after the result of testing from event organizer is positive. There is another element that needs to be involved who are sponsors. In addition, this website needs integration to existing gaming platform and social media. Also, chatting feature is also needed in this platform since this platform communication only available by commenting on certain event or brief message from event organizer when inviting player/worker.

\section{References}

[1] M. Marsyaf, "Sindo News," 2018. [Online]. Available: https://autotekno.sindonews.com/read/1347049/133/ liga-esport-terbesar-di-indonesiaberhadiah-rp3- miliar-1539792305. [Accessed: 01-Dec-2018].

[2] J. Revaro, "Skyegrid," 2018. [Online]. Available: http://media.skyegrid.id/mengenalhendry-jothree- peraih-medali-perak-game-hearthstone-di-asian- games-2018/. [Accessed: 27-Nov-2018].

[3] D. Widijatmiko, "Bola Sport," 2018. [Online]. Available: https://www.bolasport.com/sport- e/300811-ini-5-sekolah-yang-punya-program- esportsada-yang-di-indonesia. [Accessed: 27-Nov- 2018].

[4] Parbhoo, S. (2014) 'eSports Management Portal', pp. 1-64.

[5] B. S. Isman, "Smart Business Map," 2017. [Online]. Available: http://www.budiisman.com/blog/membedah-persoalan-sebuah-business-lebih-baik-secaraholistik. [Accessed: 15-Dec-2018]. 